\title{
Effect of Daily Light Integral on Composition of Hydroponic Lettuce
}

\author{
Martin P.N. Gent ${ }^{1}$ \\ Department of Forestry and Horticulture, Connecticut Agricultural Experiment \\ Station, P.O. Box 1106, New Haven, CT 06504
}

Additional index words. Lactuca sativa, light, malic acid, nitrate, reduced nitrogen, sugars

\begin{abstract}
The concentrations of metabolites in plants are affected by sunlight integral and other factors such as plant size, water content, and time of day. Tissue composition was measured for various sizes of hydroponic lettuce (Lactuca sativa L.) grown under seasonal variation in sunlight in a greenhouse and harvested in the morning or afternoon. Daily sunlight integral varied from 4 to $14 \mathrm{~mol} \cdot \mathrm{m}^{-2} \cdot$ day $^{-1}$ photosynthetically active irradiance, and plant size varied from 2 to $260 \mathrm{~g}$ fresh weight (FW)/plant in this study. Much of the variation in tissue composition on a FW basis could be explained by the increase in dry matter content with irradiance normalized per unit area. Except for nitrate, metabolite concentrations on a FW basis increased with irradiance, and the changes resulting from irradiance were greater when harvested in the afternoon than in the morning. Nitrate concentration decreased with normalized irradiance, and the trend was the same whether measured in morning or afternoon. Malic acid increased with irradiance but not enough to counter the decrease in nitrate on a charge equivalence basis. Irradiance normalized per unit leaf area explained many effects of light and plant size on dry matter content and soluble metabolite concentrations. Lettuce for human consumption is best harvested in the afternoon after growth under high light, when it has the least nitrate and more of other nutrients.
\end{abstract}

Composition of the shoot tissue of lettuce changes with environment. Light intensity or daily light integral affects the concentrations of nitrate, sugars, and other metabolites in various leafy green vegetables, including lettuce and spinach (Gruda, 2005). A study of the seasonal variation in lettuce crops grown in a greenhouse found the concentrations of nitrate decreased and sugars increased from winter to summer (Drews et al., 1995). Another study found dry matter content (the ratio of dry to FW) changed in one cultivar in response to changes in sunlight (Reinink, 1991), whereas nitrate content changed in another. There is a concern to human health regarding accumulation of a high nitrate concentration in lettuce and spinach grown under low light conditions in winter (Blom-Zandstra, 1989). High light lowers nitrate, but it can also reduce leaf quality. Tipburn, caused by a localized calcium deficiency, often occurs in hydroponic lettuce grown under high light or supplemental light (Gaudreau et al., 1994). Various studies suggest that nitrate is used as an osmoticum in lettuce and spinach. The total osmoticum was similar for lettuce grown under different light intensities, but more light increased organic acids and sucrose and decreased nitrate (Blom-Zandstra and Lampe, 1985; Burns et al., 2011b). A linear

\footnotetext{
Received for publication 30 Aug. 2013. Accepted for publication 10 Dec. 2013.

I thank Michael Short for assistance with growing, harvesting, and analysis of the plants used in this experiment.

${ }^{1}$ To whom reprint requests should be addressed; e-mail Martin.Gent@ct.gov.
}

and negative relationship between nitrate and sugar content occurred in many studies of hydroponic lettuce, as summarized by Mathieu et al. (2006). In spinach grown under low light intensity, the diurnal changes in uptake, reduction, and storage of nitrate were opposite those for amino acids or sugars (Steingrover et al., 1986). Solution electrical conductivity (EC) affected nitrate concentration in hydroponic lettuce (Gent, 2003), again suggesting a role in osmotic adjustment.

Composition of plant tissue changes with size or age. For field-grown lettuce, nitrate increased and dry matter content decreased for old or large plants (Sorensen et al., 1994). Whereas only mono- and di-saccharides predominate in young plants, sugars with three or four hexose subunits appear later (Lee and Sugiyama, 2006). This action would reduce the osmotic effect of an equal weight of sugars. A study that screened for genotype and environment effects on nitrate content found the greatest differences between cultivars in dry matter and nitrate content occurred when plants were between 50 and $100 \mathrm{~g}$ FW (Burns et al., 2011a).

The diurnal variation in metabolite concentrations is also affected by the interaction of light and plant size. In a comparison of plantings of hydroponic lettuce grown in summer or winter, there was a greater increase in dry matter content during the daylight hours in summer than in winter, and this increase was greater for small compared with large plants (Gent, 2012a). Soluble sugars were similar for all plant sizes early in the day, but they increased far more for small than large plants in the long days of summer (Gent, 2012a). In another study (Shinohara and Suzuki, 1981), sugar concentrations in lettuce were higher and varied more on sunny than cloudy days. A study comparing field-grown lettuce and spinach grown at similar temperatures but with different daylengths showed greater diurnal variation in nitrate when grown under a longer daylength (Neely et al., 2010).

It would be beneficial for growers to estimate the composition of lettuce and other leafy greens based on the environment in which the crops grow. A previous study that examined the diurnal variation in nitrate and sugars in lettuce harvested in summer and winter examined plants harvested on only two dates (Gent, 2012a). The present study examines 12 plantings grown and harvested at various times of year to quantitatively determine the trends with sunlight integral. For most plantings, harvests were done in the afternoon and early the next morning. The data were categorized by plant size, an important factor in determining composition.

\section{Materials and Methods}

Growth conditions. Plants were grown in Hamden, CT (lat. $42^{\circ} \mathrm{N}$, long. $73^{\circ} \mathrm{W}, 50 \mathrm{~m}$ ASL) in hoophouses, $17.1 \times 4.3 \times 2.7 \mathrm{~m}$ high, with a double glazing of $0.1-\mathrm{mm}$ clear polyethylene film. Heating and ventilating set points were 17 and $22{ }^{\circ} \mathrm{C}$. From mid-June to September, the houses were covered with $30 \%$ shadecloth, and the sides were left open. Each of two greenhouses had two hydroponic systems to supply growing troughs with a $1.5 \%$ slope from inlet to outlet. Each of the two systems had 12 troughs that were placed alternately along the length of the house. Each system had a reservoir into which water and nutrient concentrates were injected automatically to maintain a constant system volume and EC. The dilute solution had $8 \mathrm{~mm}$ nitrate, $4 \mathrm{~mm}$ potassium, and adequate concentrations of all other essential elements. A more detailed description is given in a previous report (Gent, 2012a).

Plant material. Seeds of butterhead lettuce (Lactuca sativa L.) cv. Buttercrunch were germinated in an artificial medium (Oasis cubes, Model LC1 Horticubes; Smithers Oasis, Kent, $\mathrm{OH}$ ) under controlled conditions. Seedlings were transplanted into the hydroponic systems at 2 weeks after germination. Plants were harvested 2 to 6 weeks after transplanting. Among the plantings harvested in the interval from July 2006 to Nov. 2008, a total of 12 were selected that did not vary in other factors such as temperature or solution composition. These plantings were grown either under a low or a high light integral from natural sunlight. For nine plantings, there were two harvests at $\approx 1500 \mathrm{HR}$ and at 0600 to $0900 \mathrm{HR}$ the next day. For three plantings, there was only one harvest, at 1200 to 1300 HR. Each planting occupied four troughs per system. Each trough had 14 plants at a density of 25 plants $/ \mathrm{m}^{2}$ before the harvest commenced. One replicate sample at each harvest was four or eight plants selected from different troughs and positions along the trough. The selected plants had neighbor plants on all sides. Whole plants were weighed. The Oasis cubes used for germination were cut off 
as were the roots below the cube. The roots were washed in tap water, dried by centrifugal force in air, weighed, and placed on dry ice. The shoot was then divided in halves or quarters, depending on plant size. One half or quarter was used for tissue analysis. One portion was weighed and put on dry ice and later lyophilized and separated into petioles and leaf blades. These tissues were reweighed and ground to pass a 20-mesh sieve. The other portion was used to determine leaf area and water content. This sample was separated into individual leaves. Each midrib or petiole was excised with a razor blade. The leaf blade was weighed and run through an area meter (Model 3000; LI-COR, Lincoln, NE) to determine leaf area. The petiole was weighed. Leaf blade and petiole samples were dried at $70^{\circ} \mathrm{C}$ and reweighed.

Analysis. Total nitrogen and elemental composition were determined as described previously (Gent, 2012a). Nitrate, amino acids, soluble sugars, and organic acids were extracted and analyzed using liquid chromatography as described previously (Gent, $2012 \mathrm{~b})$. The 12 plantings were combined for analysis of variance (ANOVA) with hydroponic systems in two greenhouses used as replicate plots within each planting. For ANOVA, light and time-of-day variables had two categories. Daily light integral over the previous $7 \mathrm{~d}$ was greater than $10 \mathrm{~mol} \cdot \mathrm{m}^{-2} \cdot \mathrm{d}^{-1}$ photosynthetically active radiation $(P A R)$ for high light and less than $6 \mathrm{~mol} \cdot \mathrm{m}^{-2} \cdot \mathrm{d}^{-1} P A R$ for low light. Time of day was either morning, 0600 to $0900 \mathrm{HR}$, or later in the day, 1200 to 1500 HR. For each planting, the plant size was split into one of three categories (small 2 to $10 \mathrm{~g} \mathrm{FW}$, medium 20 to $60 \mathrm{~g} \mathrm{FW}$, and large 80 to $300 \mathrm{~g} \mathrm{FW}$ ). These sizes were based on the weight of plants at 2,4 , or 6 weeks. The data were regressed against normalized irradiance, daily light integral divided by leaf area index. Normalized and integrated irradiance were equal if the index was less than one. The dry matter content and concentrations of each metabolite were reported on a FW basis, except total reduced nitrogen, which was on a dry weight basis. Concentrations were regressed against normalized irradiance for all size classes together.

\section{Results}

Environment. When the data were categorized for ANOVA as described previously, the daily light integral for the previous $7 \mathrm{~d}$ was $14 \mathrm{~mol} \cdot \mathrm{m}^{-2} \cdot \mathrm{d}^{-1} P A R$ under high irradiance with a range of 10.5 to 16.0 for large plants, 13.1 to 14.1 for medium plants, and a single planting at $14.1 \mathrm{~mol} \cdot \mathrm{m}^{-2} \cdot \mathrm{d}^{-1}$ for small plants. The mean value under low irradiance was $4 \mathrm{~mol} \cdot \mathrm{m}^{-2} \cdot \mathrm{d}^{-1} P A R$ with a value of 4.4 for a single planting of large plants, 3.8 to 4.2 for medium plants, and 3.8 to $4.5 \mathrm{~mol} \cdot \mathrm{m}^{-2} \cdot \mathrm{d}^{-1}$ for small plants. The irradiance in $P A R$ normalized to leaf area varied from 1.4 to 5.1 for large plants, 6.4 to 7.3 for medium plants, and 14.1 $\mathrm{mol} \cdot \mathrm{m}^{-2} \cdot \mathrm{d}^{-1}$ for small plants under high irradiance. Under low irradiance, the value was 1.2 for large plants, 1.6 to 2.2 for medium plants, and 3.8 to $4.5 \mathrm{~mol} \cdot \mathrm{m}^{-2} \cdot \mathrm{d}^{-1}$ for small plants. Day air temperature ranged from 20 to $31{ }^{\circ} \mathrm{C}$ under high irradiance and 17 to $20^{\circ} \mathrm{C}$ under low irradiance. Night air temperature ranged from 16 to $18{ }^{\circ} \mathrm{C}$ under high irradiance and 15 to $17^{\circ} \mathrm{C}$ under low irradiance.

Growth parameters. The leaf area to shoot dry weight ratio was related linearly to daily light integral (Fig. 1), although plant size also had an effect. This ratio was greatest for small plants, but small plants were least sensitive to changes in irradiance (Table 1). Whereas the relative increase in leaf area ratio from high to low light was $27 \%$ for large plants, it was only $14 \%$ for small plants. The leaf blade to whole shoot dry weight ratio also varied with plant size, but the change resulting from irradiance was small. The composition of the leaf blade differs from that in the petiole (Gent, 2012a, 2012b). However, changes in the weight ratio of these two plant parts is not likely the primary cause of changes in whole shoot composition with irradiance. Growth rate varied with irradiance or season. For plants of a given size, their age in days was $\approx 2$-fold greater under low than high irradiance.

Total reduced nitrogen. Daily light integral had no effect on total reduced nitrogen concentration in shoots of lettuce, expressed on a dry matter basis, although effects of size were significant (Table 1). Small plants had a higher nitrogen concentration than larger plants, as noted in a study of critical solution concentration of nitrate (Fontes et al., 1997). Nitrogen concentration was higher for plants harvested in morning compared with afternoon (data not shown). Usually, the tissue concentration of nitrogen decreases with irradiance, because of dilution resulting from more carbohydrate. For instance, a study of the effect of shade on greenhouse tomato found leaf nitrogen to increase with shade intensity, whereas starch decreased (Gent, 2008).

Dry matter content. Many of the trends in composition of plants on a FW basis could be explained by changes in the water content or its inverse, the dry matter content, expressed in grams dry weight per kilogram FW of the shoot. The dry matter content was sensitive to light, time of day, and plant size, and all twoway interactions were significant (Table 2). Dry matter content increased with irradiance averaged over the previous $7 \mathrm{~d}$. The sensitivity to irradiance was in the order small $>$ medium $>$ large plants. When measured in the afternoon, the increase in dry matter from low to high irradiance was $21 \%$ for medium plants and $47 \%$ for small plants. When measured in the morning, dry matter content for medium and small plants was only $15 \%$ greater when grown under high than low irradiance. A study of many lettuce cultivars grown under summer or winter conditions found a relatively small change in dry matter content from high to low light, an average of

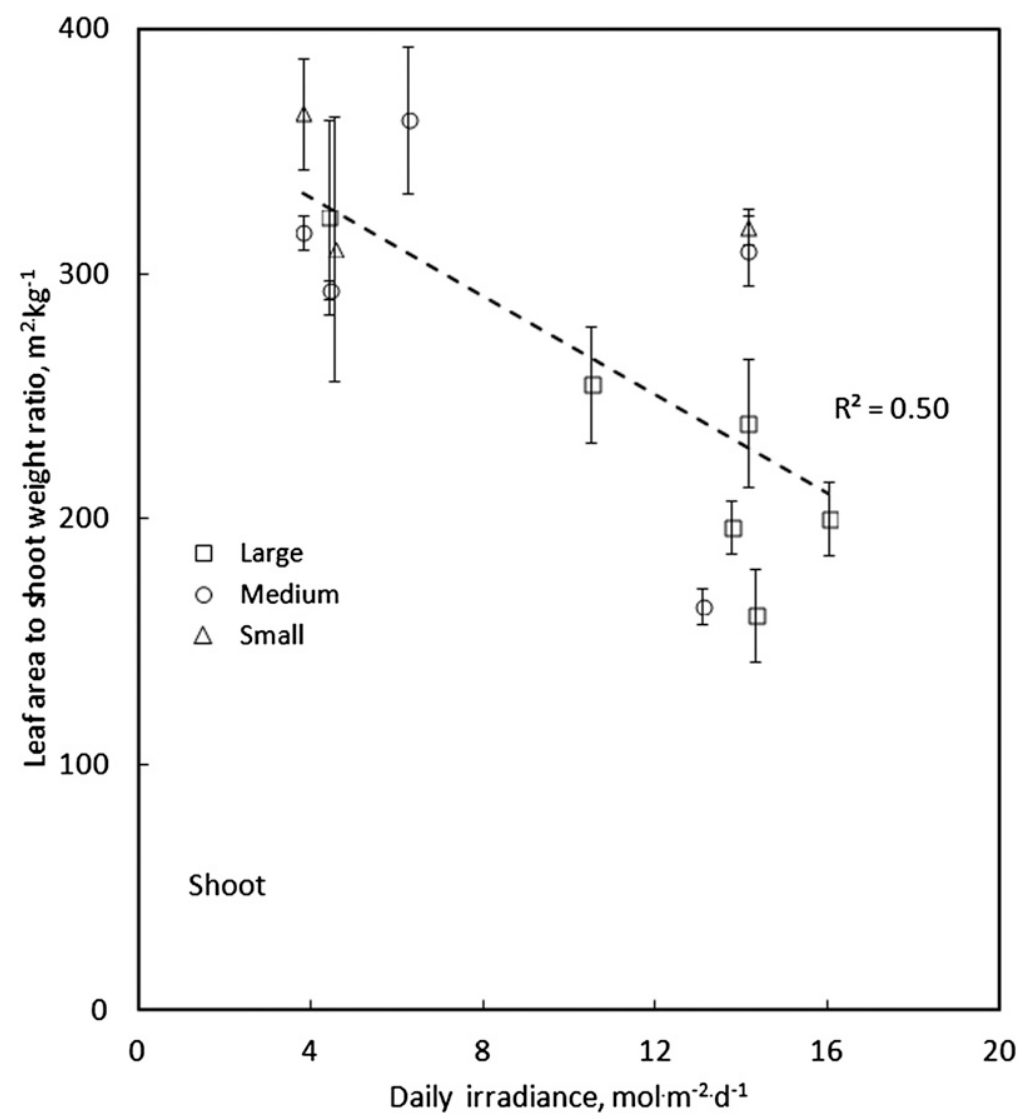

Fig. 1. Leaf area to shoot weight ratio as a function of daily integrated irradiance for hydroponic lettuce. Symbols represent data points separated by size classes; small 2 to $10 \mathrm{~g}$, medium 20 to $60 \mathrm{~g}$, and large 80 to $300 \mathrm{~g}$ fresh weight. Bars indicate the least significant difference. The linear trend is for all data. 
Table 1. Growth parameters and total nitrogen of lettuce as affected by integrated irradiance and plant size.

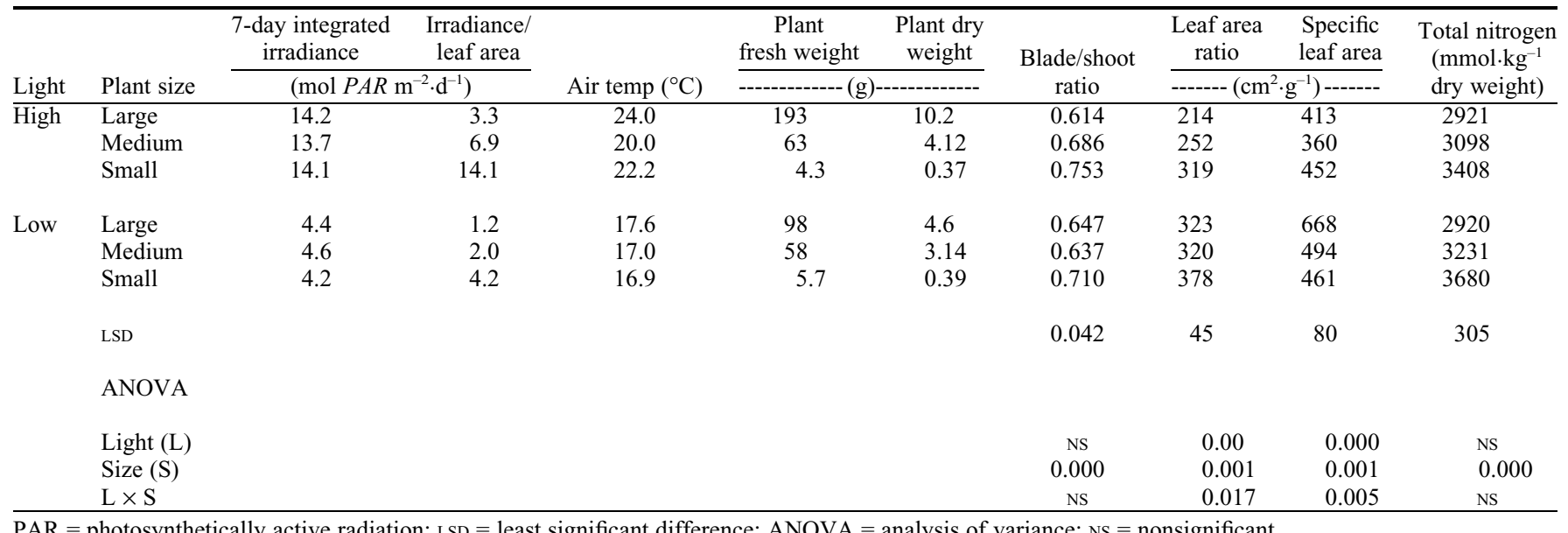

Table 2. Effect of integrated sunlight, time of day, and plant size on composition of hydroponic lettuce on a fresh weight basis.

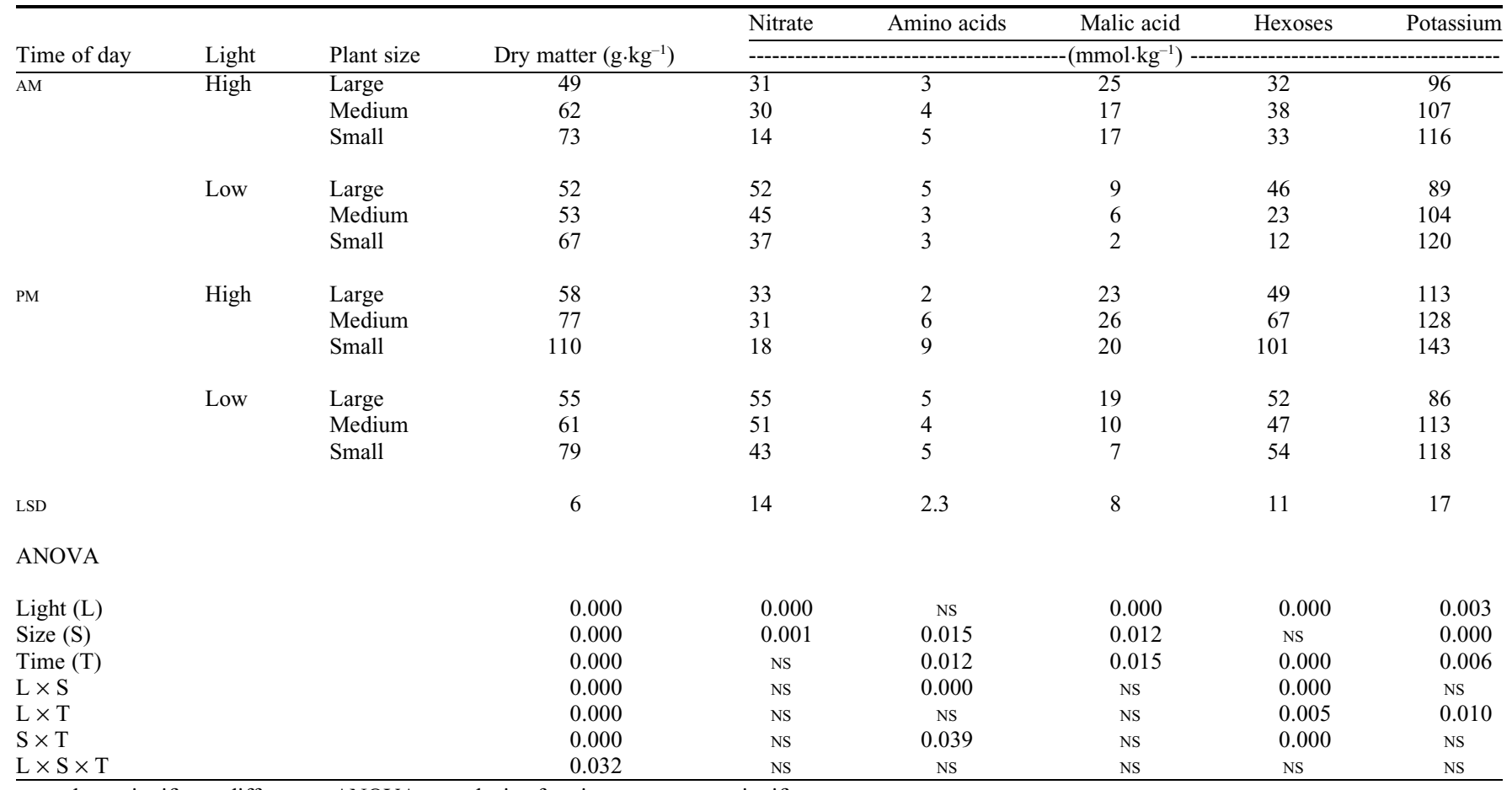

$\mathrm{LSD}=$ least significant difference; ANOVA = analysis of variance; $\mathrm{NS}=$ non-significant.

75 and $65 \mathrm{~g} \cdot \mathrm{kg}^{-1}$ (Burns et al., 2011a), perhaps because plants were of medium size and harvested early in the day. For butterhead lettuce grown in hydroponics, dry matter decreased with size from $70 \mathrm{~g} \cdot \mathrm{kg}^{-1}$ to 60 and $50 \mathrm{~g} \cdot \mathrm{kg}^{-1}$ in two cultivars (Conversa et al., 2004). For small seedlings, dry matter increased linearly from 60 to $110 \mathrm{~g} \cdot \mathrm{kg}^{-1}$ as artificial light increased from 100 to 300 $\mu \mathrm{mol} \cdot \mathrm{m}^{-2} \cdot \mathrm{s}^{-1}$ with a greater increase under 24- than 16-h photoperiod and with high $\mathrm{CO}_{2}$ compared with low $\mathrm{CO}_{2}$ (Kitaya et al., 1998). However, for hydroponic lettuce in The Netherlands, dry matter of large plants decreased from 55 to $35 \mathrm{~g} \cdot \mathrm{kg}^{-1} \mathrm{FW}$ from winter to summer (Van der Boon et al., 1990), perhaps because plant size increased, and this increase in size had more of an effect than increasing light.

The effects of irradiance and plant size on dry matter content could be accounted for by normalizing daily sunlight integral per unit leaf area. When plotted against this parameter, linear regression accounted for most of the variation in dry matter content for plants of all sizes (Fig. 2). Dry matter content in the morning varied from 50 to $75 \mathrm{~g} \cdot \mathrm{kg}^{-1}$ when normalized irradiance varied from 1 to 14 $\mathrm{mol} \cdot \mathrm{m}^{-2} \cdot \mathrm{d}^{-1}$ Shoot dry matter content changed far more with irradiance when harvested in the afternoon, near the end of the photoperiod, than when harvested in the morning, at the beginning of the photoperiod (Fig. 2). The leaf blade tissue was a factor of two more responsive than petiole tissue (data not shown). Dry matter content increased from 45 to 65 $\mathrm{g} \cdot \mathrm{kg}^{-1}$ in petioles compared with an increase from 55 to $110 \mathrm{~g} \cdot \mathrm{kg}^{-1}$ in leaf blades. Because dry matter content of hydroponic lettuce is so sensitive to irradiance, the effect of irradiance on composition differs depending on whether the results are expressed on a fresh or dry weight basis. We discuss the results for all soluble metabolites on a FW basis.

Potassium. Potassium was the cation with the highest concentration in lettuce tissue and accounted for most of the counter ions for anionic metabolites, as noted by Burns et al. (2011b). Average values exceed $100 \mathrm{mmol} \cdot \mathrm{kg}^{-1}$ compared with 10 and $30 \mathrm{mmol} \cdot \mathrm{kg}^{-1}$ for calcium in petiole and leaf blade. Potassium increased with irradiance and plant size and from morning to afternoon (Table 2). Most of the change in tissue potassium could be explained by a linear increase with normalized irradiance (Fig. 3). The increase at high irradiance was greater for plants harvested in the afternoon than in the morning, a relative increase of $50 \%$ and $20 \%$, respectively. Most of the change noted for whole shoots was the result of the change in leaf blade tissue (data 


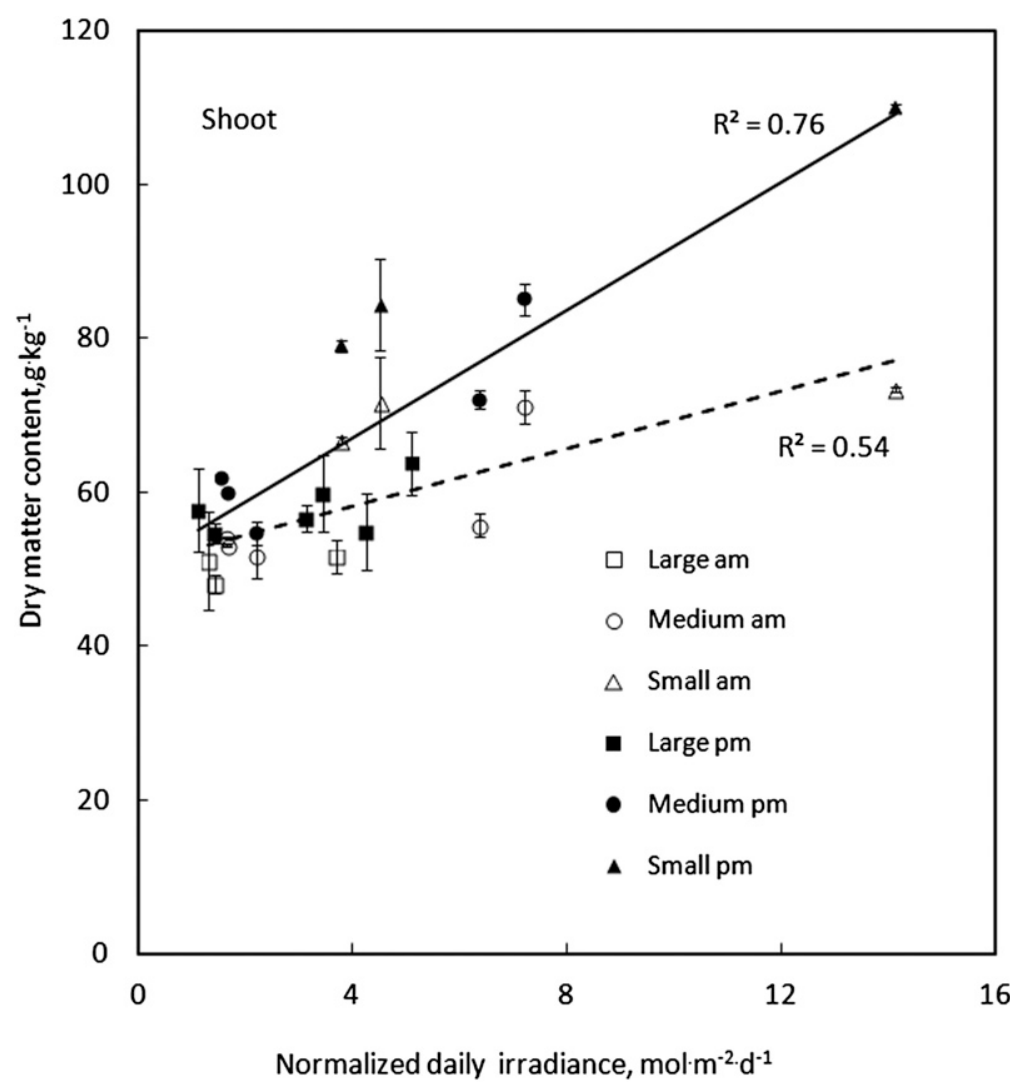

Fig. 2. Dry matter in the shoot of hydroponic lettuce on a fresh weight basis as a function of irradiance normalized per unit leaf area. Symbols represent data points separated by size classes; small 2 to $10 \mathrm{~g}$, medium 20 to $60 \mathrm{~g}$, and large 80 to $300 \mathrm{~g}$ fresh weight and time of harvest, AM or PM. Bars indicate the least significant difference. Linear trends are shown for all AM or PM data combined.

not shown). The increase in shoot potassium concentration with irradiance was less proportional than the change in dry matter content in the afternoon under high irradiance (Figs. 2 and 3). It is likely that some potassium migrated from leaf blade to stem or root tissue during the photoperiod. The concentration in roots increased by $20 \%$ as normalized irradiance increased to $14 \mathrm{~mol} \cdot \mathrm{m}^{-2} \cdot \mathrm{d}^{-1}$. In contrast, the concentrations of calcium (Fig. 4) and magnesium increased with irradiance in proportion to the increase in dry matter. As irradiance increased, calcium in shoots harvested in the afternoon increased by nearly 2 -fold, from 15 to $28 \mathrm{mmol} \cdot \mathrm{kg}^{-1}$. A comparison of two lettuce plantings found that shoot concentrations of potassium and magnesium were greater under high than low irradiance, but calcium was unaffected (Fallovo et al., 2009).

Soluble sugars. On a FW basis, sugars increased with irradiance, particularly when plants were sampled in the afternoon (Table 2). This increase was greater for small compared with large plants. However, large and medium plants had more sugars than small plants when sampled in the morning if grown under low irradiance. Sugar concentrations on a FW basis plotted against irradiance normalized to leaf area showed the same trend for all plant sizes (Fig. 5). The sugar content extrapolated to low irradiance was similar for all plant sizes. The relative increase with irradiance for sugars was greater than for dry matter when measured in the afternoon. Sugars increased from $\approx 40$ to 100 $\mathrm{mmol} \cdot \mathrm{kg}^{-1}$ as normalized irradiance increased from $\approx 2$ to $14 \mathrm{~mol} \cdot \mathrm{m}^{-2} \cdot \mathrm{d}^{-1}$. The change in sugar concentration was less in petioles, from 50 to $70 \mathrm{mmol} \cdot \mathrm{kg}^{-1}$, than in the leaf blade, from 40 to $110 \mathrm{mmol} \cdot \mathrm{kg}^{-1}$ (data not shown). Most of the change in shoot tissue was the result of the change in the leaf blade. Sugars in the whole shoot or in petiole tissue did not show any trend with irradiance when measured in the morning. The increase in sugars with irradiance in leaf blade tissue when measured in the morning was from 20 to $35 \mathrm{mmol} \cdot \mathrm{kg}^{-1}$. The concentration of sugars in roots increased with normalized irradiance when measured in the afternoon, from 15 to $30 \mathrm{mmol} \cdot \mathrm{kg}^{-1}$, whereas the concentration of sugars measured in the morning did not vary with irradiance.

One study of lettuce harvested at market size found sugars decreased with irradiance when comparing plantings in spring and summer (Fallovo et al., 2009). Another study found sugars increased with irradiance, from 36 to $44 \mathrm{mmol} \cdot \mathrm{kg}^{-1}$ of reducing sugar, for plantings done throughout the year (Drews et al., 1995). A study of lettuce at harvest size found that sugars differed on cloudy and sunny days, reaching a maximum of $\approx 25$ and $35 \mathrm{mmol} \cdot \mathrm{kg}^{-1}$ under these two conditions, respectively (Shinohara and Suzuki, 1981).
Malic acid. The primary organic acid in lettuce is malic acid. The concentration of malic acid in the shoot increased with irradiance and plant size and from morning to afternoon (Table 2). The trends with normalized irradiance for malic acid in the shoot were non-significant (Fig. 6). On average, leaf blade and petiole had similar concentrations of malic acid and similar increases with irradiance (data not shown). The roots had much less malic acid than petiole or leaf blade, but the increase in malic acid in roots with normalized irradiance was significant when measured in the afternoon, from 3 to 7 $\mathrm{mmol} \cdot \mathrm{kg}^{-1}$. Malic acid increased during the photoperiod under high irradiance in many plants with $\mathrm{C}_{3}$ metabolism (Martinoia and Rentsch, 1994).

Nitrate. Nitrate was the only metabolite we measured that decreased in concentration on a FW basis in response to daily irradiance (Table 2). Small plants had less nitrate than large plants. When plotted against irradiance normalized per unit leaf area, plants of all sizes followed a similar trend (Fig. 7), whether harvested in morning or afternoon. Nitrate in leaf blades decreased from 35 to 10 $\mathrm{mmol} \cdot \mathrm{kg}^{-1}$, whereas that in petioles decreased from 50 to $30 \mathrm{mmol} \cdot \mathrm{kg}^{-1}$ as irradiance increased from $\approx 2$ to $14 \mathrm{~mol} \cdot \mathrm{m}^{-2} \cdot \mathrm{d}^{-1}$. The nitrate concentration in roots varied little with irradiance when measured in either morning or afternoon and averaged 40 to 50 $\mathrm{mmol} \cdot \mathrm{kg}^{-1}$. A difference in nitrate content resulting from plant size was noted in a study of critical nitrate concentration in lettuce (Fontes et al., 1997). Burns et al. (2011a) found that nitrate concentration increased with head weight, at least up to $100 \mathrm{~g} \mathrm{FW}$. However, Drews et al. (1995) found that nitrate decreased with head weight, when head weight increased with seasonal radiation in a greenhouse. An earlier study of hydroponic lettuce grown in a greenhouse in Connecticut found a 2- to 3-fold greater nitrate concentration in winter than in summer, a range of 32 to $54 \mathrm{mmol} \cdot \mathrm{kg}^{-1}$ in winter and 18 to $19 \mathrm{mmol} \cdot \mathrm{kg}^{-1}$ in summer (Gent, 2003). Nitrate concentration decreased from 78 to $45 \mathrm{mmol} \cdot \mathrm{kg}^{-1}$ from winter to summer in crops of hydroponic lettuce in The Netherlands (Van der Boon et al., 1990), and a similar seasonal variation was noted in another study of soil-grown greenhouse lettuce (Drews et al., 1995) and in studies under artificial light (Blom-Zandstra and Lampe, 1985). For hydroponic lettuce in a greenhouse, leaf nitrate increased from 61 to 77 $\mathrm{mmol} \cdot \mathrm{kg}^{-1}$ early in the night before falling to a lower value early in the day (Carrasco and Burrage, 1993).

\section{Discussion}

This study of composition of hydroponic lettuce found that plant size and time of day were important factors that affected the responses of metabolite concentrations to sunlight integral. Time of day had a greater effect when plants were grown under high light intensity in summer than when plants were 


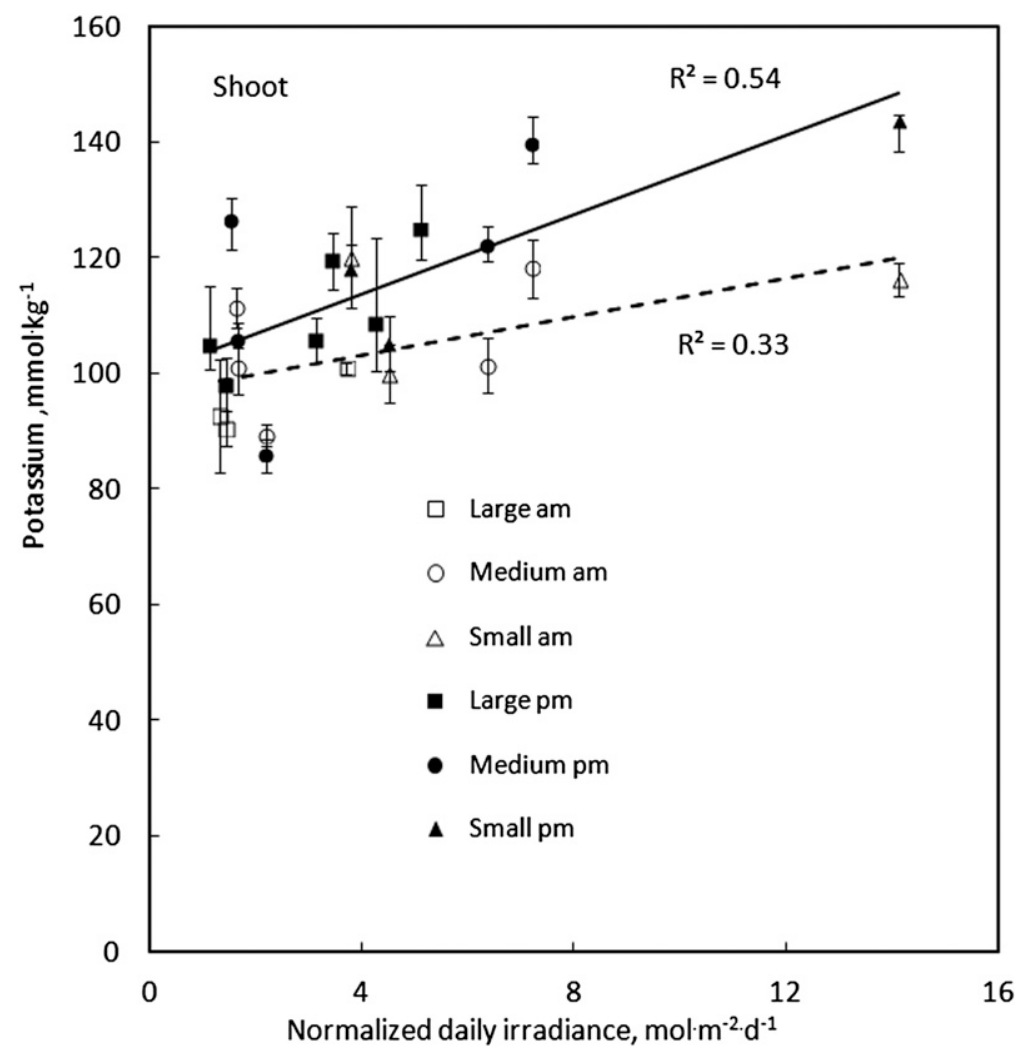

Fig. 3. Potassium concentration in the shoot of hydroponic lettuce on a fresh weight basis as a function of irradiance normalized per unit leaf area. Symbols represent data points separated by size classes; small 2 to $10 \mathrm{~g}$, medium 20 to $60 \mathrm{~g}$, and large 80 to $300 \mathrm{~g}$ fresh weight, and time of harvest, AM or PM. Bars indicate the least significant difference. Linear trends are shown for all AM or PM data combined.

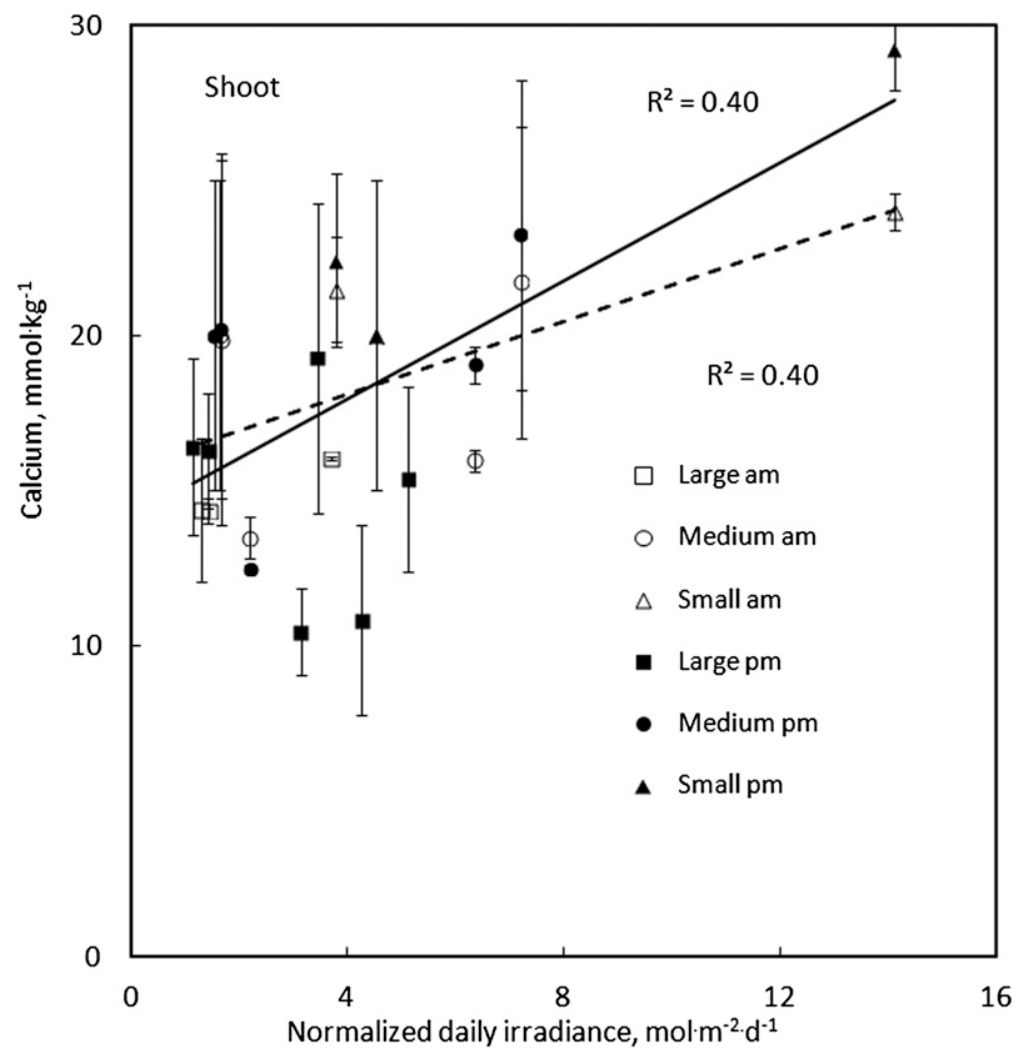

Fig. 4. Calcium concentration in the shoot of hydroponic lettuce on a fresh weight basis as a function of irradiance normalized per unit leaf area. Symbols represent data points separated by size classes; small 2 to $10 \mathrm{~g}$, medium 20 to $60 \mathrm{~g}$, and large 80 to $300 \mathrm{~g}$ fresh weight and time of harvest, AM or PM. Bars indicate the least significant difference. Linear trends are shown for all AM or PM data combined. grown under low light intensity and relatively constant temperature in winter, as noted earlier for nitrate and sugars (Gent, 2012a). When irradiance was normalized per unit leaf area, like in Figures 2 to 7, it accounted for most of the effects of plant size on tissue contents.

Plants of different sizes vary in leaf area index and light interception per unit leaf area or weight. Leaves of small plants are widely spaced and they are exposed to the full intensity of sunlight falling on the canopy. Larger plants have more leaf area and considerable overlap of leaves, so on average, light intensity per unit leaf area is less. As a result of the greater light intensity per unit leaf area, at a given sunlight integral per unit ground area, small plants would be expected to have higher rates of photosynthesis and nitrate reduction and, thus, greater changes in sugars and nitrate than large plants. Another factor that likely varied with plant size was the rate of metabolism per unit weight, as noted for lettuce by Van Iersel (2003). In our study, small plants had a lower concentration of sugars in the morning than large plants. This was likely the result of more rapid metabolism in small plants through the previous night, because small plants had more sugars than large plants near the end of the day (Table 2).

The lettuce shoot is made up of different tissues, namely leaf blade and petiole, which differ in composition (Gent, 2012a). As a fraction of shoot weight, petioles increased from $25 \%$ to $40 \%$ of the total on a dry weight basis as lettuce plants increased in size (Table 1). The weight fraction can increase to $50 \%$ or more on a FW basis, because petioles have a greater water content than leaf blades (Gent, 2012a). Although not reported here, dry matter content of the petiole was less sensitive than the leaf blade to diurnal variation or sunlight intensity. The greater contribution of petiole tissue to shoot biomass would explain, in part, the relatively smaller response to irradiance of metabolites in large than small plants as well as the relatively high concentration of sugars and nitrate in large plants.

Previous research showed that petioles of lettuce had more sugar than leaf blades at dawn, and sugars increased more slowly, but for a longer duration of the daylight hours, than in leaf blades (Gent, 2012a). There was a higher concentration of nitrate in petiole than leaf blade tissue at all times (Gent, 2012a). Studies of spinach noted more nitrate in petioles than leaves and a greater diurnal variation in leaves (Steingrover et al., 1986). The nitrate concentration in spinach shoots at the end of the day was lowered by increasing light intensity (Scaife and Schloemer, 1994), and the variation in nitrate resulting from light intensity was less in the root and petiole than in the leaf blade. The lack of diurnal variation in nitrate on a FW basis was noted for root and petiole of tomato (CardenasNavarro et al., 1999). The only diurnal variation was in leaf blade tissue.

An inverse pattern of variation in sugars plus organic acids compared with nitrate, increasing for sugars and decreasing for 


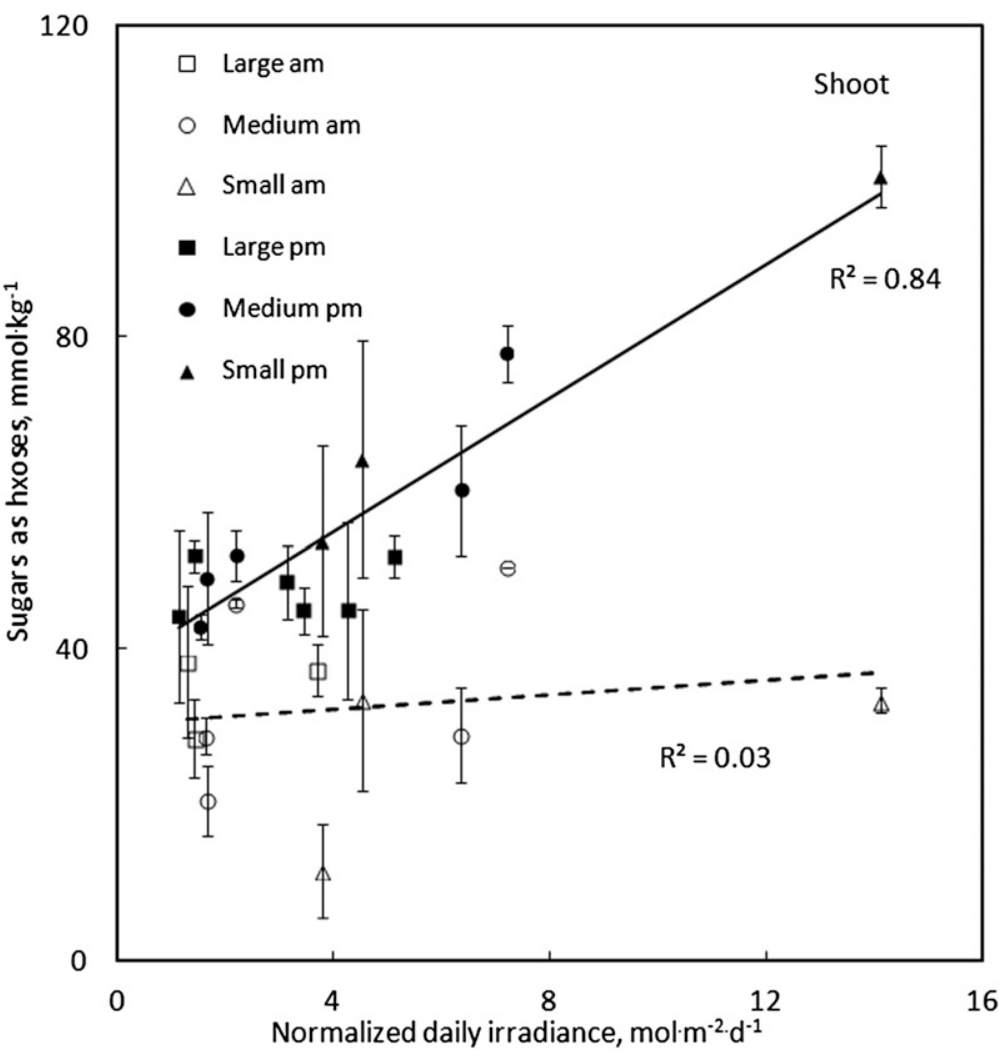

Fig. 5. Soluble sugar concentration as hexoses in the shoot of hydroponic lettuce on a fresh weight basis as a function of irradiance normalized per unit leaf area. Symbols represent data points separated by size classes; small 2 to $10 \mathrm{~g}$, medium 20 to $60 \mathrm{~g}$, and large 80 to $300 \mathrm{~g}$ fresh weight and time of harvest, AM or PM. Bars indicate the least significant difference. Linear trends are shown for all am or pm data combined.

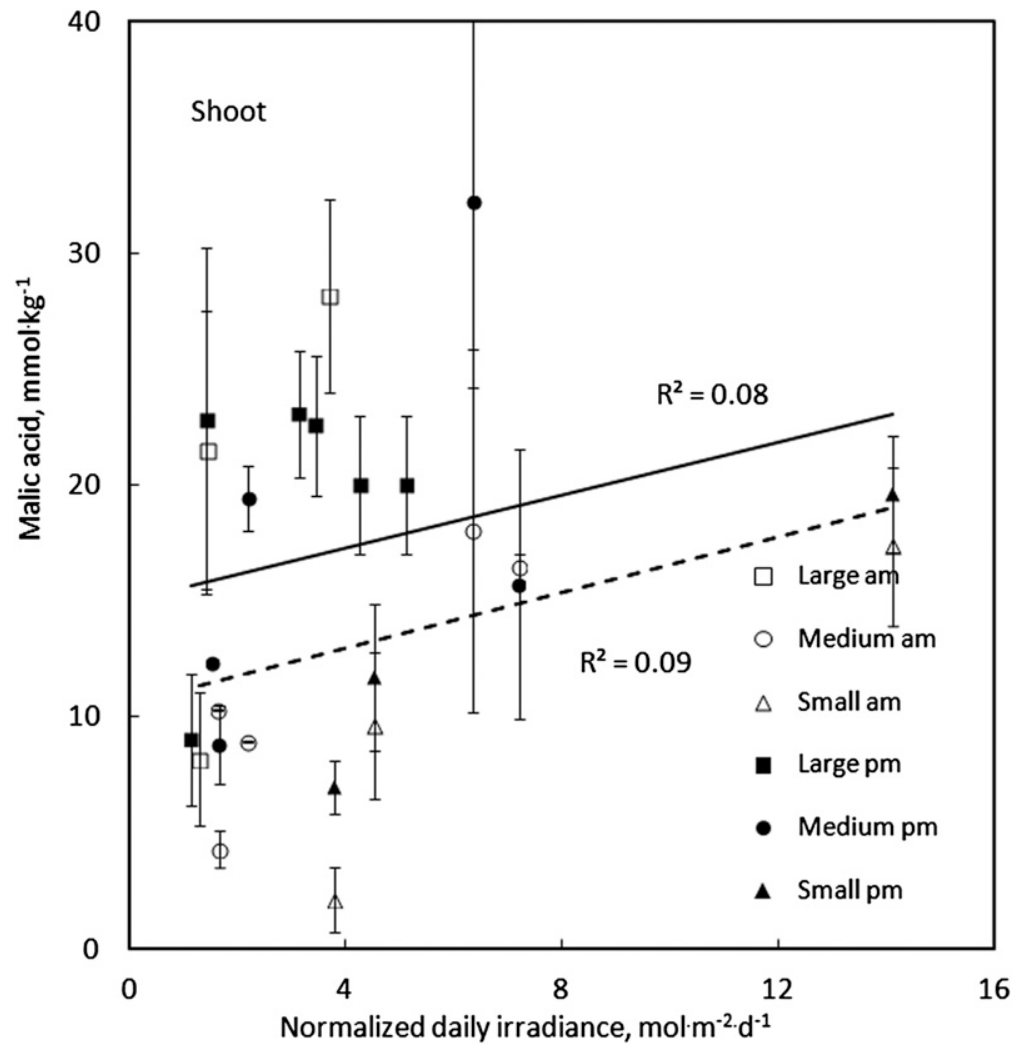

Fig. 6. Malic acid concentration in the shoot of hydroponic lettuce on a fresh weight basis as a function of irradiance normalized per unit leaf area. Symbols represent data points separated by size classes; small 2 to $10 \mathrm{~g}$, medium 20 to $60 \mathrm{~g}$, and large 80 to $300 \mathrm{~g}$ fresh weight and time of harvest, AM or PM. Bars indicate the least significant difference. Linear trends are shown for all AM or PM data combined. nitrate, was reported in studies of hydroponic lettuce (Mathieu et al., 2006). One hypothesis is that this change was the result of a requirement for a stable osmotic potential in plant tissue (Blom-Zandstra and Lampe, 1985; Steingrover et al., 1993). A study of all of the main soluble components of lettuce found a similar inverse relation of all other solutes with nitrate content to maintain a constant osmoticum (Burns et al., 2011b). The changes in malic acid observed here were opposite but quantitatively less than that of nitrate when expressed on a charge equivalence basis, two equivalents per mole of malic acid and one per mole of nitrate. The increase in potassium concentration on a FW basis was less than expected simply for the loss of cell water, indicating a movement of potassium out of shoots under high irradiance. Other anions such as chloride and phosphate contributed an average of 20 meq $\cdot \mathrm{kg}^{-1}$, which was in the range of 10 to $30 \mathrm{meq} \cdot \mathrm{kg}^{-1}$ seen in another study of hydroponic lettuce (Burns et al., 2011b). We found no significant trends with irradiance for chloride and phosphate, whereas all cations showed an increase. This increase was proportional to the increase in dry matter content for calcium and magnesium but less than proportional for potassium. The sum of anions showed no trend or a slight decrease with irradiance, whereas the sum of cations showed an increase from 120 to $200 \mathrm{meq} \cdot \mathrm{kg}^{-1}$. Consequently, the difference between the measured anions and cations increased with irradiance. The surplus of cation equivalents was $\approx 60 \mathrm{meq} \cdot \mathrm{kg}^{-1}$ under low irradiance, increasing to $140 \mathrm{meq} \cdot \mathrm{kg}^{-1}$ for small plants under high irradiance. Presumably other cell components such as proteins and lipids as well as soluble metabolites that were not analyzed accounted for the missing anions. These would increase in concentration on a FW basis as plants lost water during the day. In another study of hydroponic lettuce, the total solutes, other than nitrate, decreased with plant size, from 300 to $380 \mathrm{meq} \cdot \mathrm{kg}^{-1}$ for small plants to as low as $150 \mathrm{meq} \cdot \mathrm{kg}^{-1}$ for large plants (Burns et al., 2011b). This trend is consistent with the values observed here.

Cardenas Navarro et al. (1999) hypothesized that the concentration of nitrate in plant tissue water was relatively constant and that changes in concentration on a dry matter basis reflected changes in water content. Clearly this was not the case in the present study for hydroponic lettuce exposed to a wide range in sunlight intensity. The decrease in nitrate concentration with irradiance on a FW basis indicated the amount of nitrate in plant tissue decreased proportionally more than the loss of tissue water. This result occurred whether plants were measured in the afternoon, when shoot water content was affected markedly by irradiance, or in the morning, when effects of average irradiance on dry matter or water content were much less (Fig. 3).

On a FW basis, the change in concentration of metabolites with irradiance was 


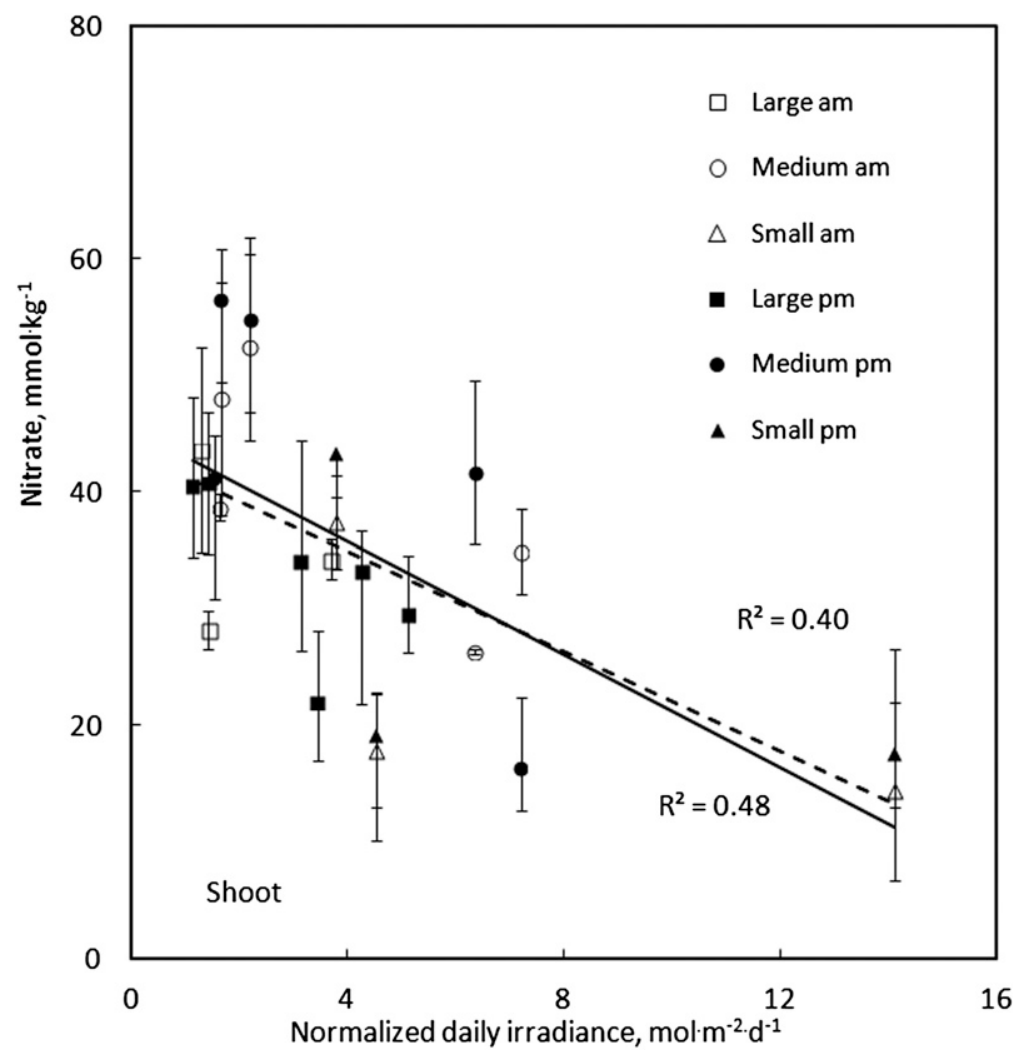

Fig. 7. Nitrate concentration in the shoot of hydroponic lettuce on a fresh weight basis as a function of irradiance normalized per unit leaf area. Symbols represent data points separated by size classes; small 2 to $10 \mathrm{~g}$, medium 20 to $60 \mathrm{~g}$, and large 80 to $300 \mathrm{~g}$ fresh weight, and time of harvest, AM or PM. Bars indicate the least significant difference. Linear trends are shown for all AM or PM data combined.

greater when plants were harvested in the afternoon than in the morning. For plants harvested in the morning, significant trends with irradiance were seen for dry matter content, nitrate, and each of the cations. The larger variation in dry matter or water content and metabolite concentrations on FW basis in the afternoon compared with the morning suggests that lettuce plants did not maintain a constant osmoticum over the diurnal cycle when grown under high irradiance. However, after recovery in darkness, the plants should have been able to achieve a stable osmoticum. Nevertheless, the trends with average irradiance when plants were harvested in the morning suggest that this phenomenon was not the case for dry matter content, nitrate, and cations. We found the osmoticum of hydroponic lettuce was not constant under all environmental conditions and particular not under wide variations in sunlight intensity. Lettuce for human consumption was best harvested in the afternoon after growth under high light.

\section{Literature Cited}

Blom-Zandstra, M. 1989. Nitrate accumulation in vegetables and its relationship to quality. Ann. Appl. Biol. 115:553-561.

Blom-Zandstra, M. and J.E.M. Lampe. 1985. The role of nitrate in the osmo-regulation of lettuce (Lactuca sativa $\mathrm{L}$ ) grown at different light intensities. J. Expt. Bot. 36:1043-1052.

Burns, I.G., K. Zhang, M.K. Turner, M. Meacham, K. Al-Redhiman, J. Lynn, M.R. Broadley,
P. Hand, and D. Pink. 2011a. Screening for genotype and environment effects on nitrate accumulation in 24 species of young lettuce. J. Sci. Food Agr. 91:553-562.

Burns, I.G., K. Zhang, M.K. Turner, and R. Edmondson. 2011b. Iso-osmotic regulation of nitrate accumulation in lettuce. J. Plant Nutr. 34:283-313.

Cardenas-Navarro, R., S. Adamowicz, and P. Robin. 1999. Nitrate accumulation in plants: A role for water. J. Expt. Bot. 50:613-624.

Carrasco, G.A. and S.W. Burrage. 1993. Diurnal fluctuations in nitrate accumulation and reductase activity in lettuce (Lactuca sativa $\mathrm{L}$ ) grown using nutrient film technique. Acta Hort. 323: $51-59$.

Conversa, G., P. Santamaria, and M. Gonnella. 2004. Growth, yield, and mineral composition of butterhead lettuce (Lactuca sativa var capitata) grown in NFT. Acta Hort. 659:621-628.

Drews, M., I. Schonhof, and A. Krumbein. 1995. Influence of growth season on the content of nitrate, vitamin-C, beta-carotene, and sugar of head lettuce under greenhouse conditions. [in German] Gartenbauwissenschaft 60:180-187.

Fallovo, C., Y. Rouphael, E. Rea, A. Battistelli, and G. Colla. 2009. Nutrient solution concentration and growing season affect yield and quality of Lactuca sativa L. var. acephala in floating raft culture. J. Sci. Food Agr. 89: 1682-1689.

Fontes, P.C.R., P.R.G. Pereira, and R.M. Conde. 1997. Critical chlorophyll, total nitrogen, and nitrate-nitrogen in leaves associated to maximum lettuce yield. J. Plant Nutr. 20:1061-1068.

Gaudreau, L., J. Charbonneau, L.P. Vezina, and A. Gosselin. 1994. Photoperiod and photosynthetic photon flux influence growth and quality of greenhouse-grown lettuce. HortScience 29 : 1285-1289.

Gent, M.P.N. 2003. Solution electrical conductivity and ratio of nitrate to other nutrients affect accumulation of nitrate in hydroponic lettuce. HortScience 38:222-227.

Gent, M.P.N. 2008. Density and duration of shade affect water and nutrient use in greenhouse tomato. J. Amer. Soc. Hort. Sci. 133:619-627.

Gent, M.P.N. 2012a. Composition of hydroponic lettuce: Effect of time of day, plant size, and season. J. Sci. Food Agr. 92:542-550.

Gent, M.P.N. 2012b. Rate of change of composition of lettuce in response to nitrogen depletion or resupply. J. Sci. Food Agr. 92:3007-3015.

Gruda, N. 2005. Impact of environmental variables on product quality of greenhouse vegetables for fresh consumption. Crit. Rev. Plant Sci. 24:227-247.

Kitaya, Y., G.H. Niu, T. Kozai, and M. Ohashi. 1998. Photosynthetic photon flux, photoperiod, and $\mathrm{CO}_{2}$ concentration affect growth and morphology of lettuce plug transplants. HortScience 33:988-991.

Lee, O. and N. Sugiyama. 2006. Changes in carbohydrate composition in lettuce flower stalks during development. J. Hortic. Sci. Biotechnol. 81:928-932.

Martinoia, E. and D. Rentsch. 1994. Malate compartmentation-Response to a complex metabolism. Ann. Rev. Plant Physiol. Mol. Biol. 45: 447-467.

Mathieu, J., R. Linker, L. Levine, L. Albright, A.J. Both, R. Spanswick, R. Wheeler, E. Wheeler, D. Devilliers, and R. Langhans. 2006. Evaluation of the Nicolet model for simulation of short-term hydroponic lettuce growth and nitrate uptake. Biosystems Eng. 95:323-337.

Neely, H.L., R.T. Koenig, C.A. Miles, T.C. Koenig, and M.G. Karlsson. 2010. Diurnal fluctuation in tissue nitrate concentration of field grown leafy greens at two latitudes. HortScience 45:1815-1818

Reinink, K. 1991. Genotype $\times$ environment interaction for nitrate concentration in lettuce. Plant Breed. 107:39-49.

Scaife, A. and S. Schloemer. 1994. The diurnal pattern of nitrate uptake and reduction by spinach (Spinacia oleracea L). Ann. Bot. (Lond.) 73:337-343.

Shinohara, Y. and Y. Suzuki. 1981. Effects of light and nutritional conditions on the ascorbic acid content of lettuce. J. Jpn. Soc. Hort. Sci. 50:239-246.

Sorensen, J.N., A.S. Johansen, and N. Poulsen. 1994. Influence of growth conditions on the value of crisphead lettuce 1) Marketable and nutritional quality as affected by nitrogen supply cultivar and plant age. Plant Foods Hum. Nutr. 46:1-11.

Steingrover, E., P. Ratering, and J. Siesling. 1986. Daily changes in uptake, reduction and storage of nitrate in spinach grown at low lightintensity. Physiol. Plant. 66:550-556.

Steingrover, E.G., J.W. Steenhuizen, and J. Vanderboon. 1993. Effects of low-light intensities at night on nitrate accumulation in lettuce grown on a recirculating nutrient solution. Neth. J. Agr. Sci. 41:13-21.

Van der Boon, J., J.W. Steenhuizen, and E.G. Steingrover. 1990. Growth and nitrate concentration of lettuce as affected by total nitrogen and chloride concentration, $\mathrm{NH} 4 / \mathrm{NO} 3$ ratio and temperature of the recirculating nutrient solution. J. Hort. Sci. 65:309-321.

Van Iersel, M.W. 2003. Carbon use efficiency depends on growth respiration, maintenance respiration, and relative growth rate. A case study with lettuce. Plant Cell Environ. 26: 1441-1449. 